Revista de la red interuniversitaria de estudios sobre las literaturas rioplatenses contemporáneas en Francia

$18 \mid 2018$

El río y la ciudad

\title{
El río y la ciudad en la obra de Marcelo Cohen
}

Ricardo Torre

OpenEdition

Journals

Edición electrónica

URL: http://journals.openedition.org/lirico/5629

DOI: $10.4000 /$ lirico.5629

ISSN: 2262-8339

Editor

Réseau interuniversitaire d'étude des littératures contemporaines du Río de la Plata

Referencia electrónica

Ricardo Torre, «El río y la ciudad en la obra de Marcelo Cohen », Cuadernos LIRICO [En línea], 18 | 2018,

Puesto en línea el 11 octubre 2018, consultado el 30 abril 2019. URL : http://journals.openedition.org/ lirico/5629 ; DOl : 10.4000/lirico.5629

Este documento fue generado automáticamente el 30 abril 2019.

\section{(c) $(\mathbb{0} \Theta \Theta$}

Cuadernos LIRICO está distribuido bajo una Licencia Creative Commons Atribución-NoComercialSinDerivar 4.0 Internacional. 


\title{
El río y la ciudad en la obra de Marcelo Cohen
}

\author{
Ricardo Torre
}

1 Marcelo Cohen (Buenos Aires, 1951) es un escritor argentino prolífico -en más de cuarenta años de producción desde 1972 lleva publicados unos veinte libros de narrativaque ha sabido construir sólidamente un universo literario con múltiples modulaciones ${ }^{1}$. A pesar de la variedad importante de recursos, temas, registros que puede encontrarse en su obra, un criterio que nos permite efectuar un intento de periodización es el espacial. Su producción literaria podría, entonces, estudiarse de la manera siguiente, agregando al criterio citado la década de escritura:

2 1. Ciclo de libros de juventud: escritos en los años 70 en Argentina, los libros de cuentos Lo que queda (1972) y Los pájaros también se comen (1975) tienen como escenario exclusivo la ciudad de Buenos Aires.

3 2. Ciclo del exilio barcelonés²: en las décadas de los 80 y 90, entre 1981 y 1995, las novelas y volúmenes de relatos publicados por nuestro autor -fundamentalmente en Barcelonavan despegándose cada vez más del referente urbano real. De Buenos Aires, que alberga ya desde El instrumento más caro de la Tierra (1981) un suburbio conjetural llamado Villa Canedo, y de tímidas apariciones de referentes europeos, el centro de la acción narrativa se desplaza a centros urbanos imaginarios, en Argentina (Bardas de Krámer) o en lugares o países anónimos. En general se trata de ciudades posindustriales.

4 3. Ciclo del Delta Panorámico: a partir de 2001, la casi totalidad de la producción de Cohen tiene como espacio de la acción narrativa un conjunto de ciudades-islas inventadas, ubicadas en un futuro lejano, en una zona atópica llamada "Delta Panorámico".

5 Entre los dos últimos ciclos, podríamos citar la novela corta Impureza, publicada en un principio en 2004 en una antología de diez cuentos sobre tango de autores diferentes ${ }^{3}$ y reeditada en volumen separado en $2007^{4}$. Esta singular novela (corta) híbrida ${ }^{5}$ podría considerarse como una transición entre el mundo posindustrial de las historias de los años 80 y 90 y el mundo del Delta Panorámico del nuevo milenio. En efecto, Impureza se centra espacialmente en una villa de emergencia de un suburbio de la capital 
posindustrial de un país anónimo y toma prestado el universo de ciencia ficción del Delta Panorámico sin tener lugar su acción en su geografía imaginaria.

6 El cuadro siguiente esquematiza la producción coheniana ${ }^{6}$ según los criterios esbozados anteriormente:

Cuadro: Selección de la obra de Marcelo Cohen según criterios témporo-espaciales.

\begin{tabular}{|c|c|c|}
\hline $\begin{array}{l}\text { Recorte temporal } \\
\text { en ciclos }\end{array}$ & Obras & Espacios \\
\hline \multirow{2}{*}{$\begin{array}{l}\text { Década del 70: } \\
\text { Ciclo de libros de } \\
\text { juventud }\end{array}$} & Lo que queda & \multirow{3}{*}{ Buenos Aires } \\
\hline & Los pájaros también se comen & \\
\hline \multirow{7}{*}{$\begin{array}{l}\text { Décadas del } 80 \text { y } \\
\text { del 90: } \\
\text { Ciclo del exilio } \\
\text { barcelonés }\end{array}$} & El instrumento más caro de la Tierra & \\
\hline & El país de la dama eléctrica $(\mathrm{N})$ & $\begin{array}{l}\text { Suburbio inventado de } \\
\text { Buenos Aires (Villa Canedo) }\end{array}$ \\
\hline & Insomnio $(\mathrm{N})$ & Bardas de Krámer \\
\hline & El oído absoluto $(\mathrm{N})$ & Lorelei \\
\hline & El fin de lo mismo & ciudades posindustriales \\
\hline & El testamento de O'Jaral $(\mathrm{N})$ & Talecuona \\
\hline & Inolvidables veladas $(\mathrm{N})$ & ciudad del tango \\
\hline$(2004 / 2007)$ & Impureza $(\mathrm{N})$ & $\begin{array}{l}\text { suburbios de una capital } \\
\text { posindustrial futurista }\end{array}$ \\
\hline $\begin{array}{l}\text { A partir de 2001: } \\
\text { Ciclo del Delta } \\
\text { Panorámico }\end{array}$ & $\begin{array}{l}\text { Los acuáticos, Donde yo no estaba (N), Casa de } \\
\text { Ottro }(\mathrm{N}), \text { Balada }(\mathrm{N}) \text {, Gongue... (N) }\end{array}$ & $\begin{array}{l}\text { ciudades-islas del } \\
\text { Delta Panorámico }\end{array}$ \\
\hline
\end{tabular}

7 Este cuadro nos permite confirmar fácilmente una observación realizada por los críticos: "la preponderancia de la ciudad en [la] narrativa"7 de Marcelo Cohen. A continuación proponemos, en consecuencia, realizar una síntesis crítica de los estudios cuyo núcleo ha sido la ciudad en nuestro autor.

\section{La ciudad en Cohen: un intento de sistematización}

Pasemos revista a las principales ciudades que se han analizado en la crítica coheniana:

9 Bardas de Krámer. Es la ciudad a la que se han dedicado seguramente más estudios académicos que a cualquier otro conjunto urbano. Recordemos que se trata de la ciudad patagónica inventada en Insomnio. Siguiendo la clasificación espacial propuesta por Bertrand Westphal en su teoría geocrítica, estaríamos en presencia de un caso de "interferencia heterotópica", el de la "interpolación", es decir: la inclusión en un 
referente espacial conocido (la Patagonia argentina) de un espacio imaginario ${ }^{10}$. Es una ciudad agonizante y decadente ${ }^{11}$ que se fundó "sobre una promesa fallida" ${ }^{12}$ : pozos de petróleo que se secaron con el tiempo. Se han puesto de relieve para este centro urbano las condiciones nefastas producidas por la desindustrialización y las consecuencias extremas de un modelo socioeconómico y político neoliberal ${ }^{13}$. Fenómenos migratorios particulares y medidas políticas coercitivas han terminado por asimilar el enclave patagónico de Insomnio a una Babilonia desterritorializada ${ }^{14}$, entrópica y semivacía ${ }^{15}$ : luego de la llegada de olas migratorias de individuos de todos los países del mundo, el agotamiento de los pozos de petróleo desencadenó éxodos masivos de hordas de desempleados por toda América Latina. Del crecimiento caótico inicial, pasamos a un caos generalizado por los desmanes provocados por los desocupados en otras ciudades latinoamericanas. Para poner fin a la barbarie, las instancias políticas deciden impedir la emigración libre de Krámer y la limitan a la salida por sorteo de diez habitantes por día. De ahí que este espacio virtual distópico ha sido comparado a una prisión ${ }^{16}$. Por último, Krámer concentraría características de una ciudad panóptica y posapocalíptica ${ }^{17}$. Panóptica simplemente porque todos los ciudadanos pueden ser espías y delatar a quien quisiera escapar; el Estado tiene así ojos en todas partes. Posapocalíptica según la interpretación que define la ciencia ficción posapocalíptica (en la producción argentina posdictatorial) como una ficción que radicaliza tendencias del presente en un espacio barbarizado y desintegrado después de un cataclismo de grandes magnitudes ${ }^{18}$.

10 Lorelei. Más que una ciudad, Lorelei es un conjunto urbano asentado en dos islas intercomunicadas y que poseen un sector periférico. Escenario de El oído absoluto, Lorelei esconde más de lo que exhibe: si en las apariencias es un centro vacacional internacional que se pretende totalmente utópico, no todo es color de rosa en esta falsa isla de la fantasía. Además del reflejo de un mundo ultracapitalista y globalizado en donde reina la mezcolanza de productos y de gente, se puede destacar que Lorelei funciona también simbólicamente como una cárcel para una parte de la población: los indefinidos sociales que son sus "residentes forzosos". La utopía se revela una clara distopía totalitaria al final de la novela" ${ }^{19}$.

11 Talecuona. "Agonizante metrópoli ficticia"20 de un país latinoamericano anónimo, la ciudad de El testamento de O'Jaral se caracteriza por la fragmentación urbana, el colapso social que tiende a separar a los habitantes según su nivel económico, los efectos nefastos de la industrialización y de la contaminación consecuente y la pobreza. Esta ciudad ha sido comparada a un organismo enfermo ${ }^{21}$. Nacida en un marco distópico, sería también un espacio posapocalíptico en la medida en que en ella se radicalizan tendencias del presente.

12 Algunas de estas características se han empleado para calificar los espacios urbanos de otras ficciones cohenianas: la fragmentación urbana se ha aplicado a los suburbios de Impureza ${ }^{22}$; se ha hablado de ciudad panóptica y decadente para una de las ciudades-islas del Delta Panorámico, La Bruya, del relato "Cuando aparecen Aquéllos" de Los acuáticos"23.

13 Hemos visto con estos rasgos que la ciudad en Cohen vehicularía casi exclusivamente una gran carga disfórica. Proponemos indicar una interpretación que contemple de manera integral una axiología que recupere lo urbano en la producción de Cohen.

14 Ya sea antes o después de 2001, con la creación del Delta Panorámico, la ciudad es un "elemento-sistema" íntimamente ligado a los universos de ficción cohenianos. La ciudad es un "elemento" clave o pieza central en el mecanismo y en la estructura narrativa de Cohen: si la quitamos del relato, el relato se desploma. Por eso, es un componente esencial 
y constitutivo de sus construcciones ficcionales. La ciudad es asimismo un "sistema" de relaciones topográficas que integra y conecta subunidades geográficas (los barrios, los suburbios, el centro, las villas miseria...). Si queremos abarcar la mayor parte de la producción de Cohen, teniendo en mente un objetivo y un estudio transversales, debemos trazar un itinerario, un recorrido espacial que se origina en Buenos Aires ${ }^{24}$, prosigue en metrópolis imaginarias (Bardas de Krámer ${ }^{25}$, Talecuona ${ }^{26} . .$. ) y concluye en las ciudadesislas del Delta Panorámico. Una parte de la crítica hace hincapié en el carácter patológico de la ciudad coheniana ${ }^{27}$ :

El espacio urbano es un espacio desolado, escenario de las frustraciones de la modernidad como en El testamento de O'Jaral, o literalmente quiste sin futuro como en Insomnio, o peor, un barrio temático y virtual colgado del holograma de una leyenda, un espejismo, como en Inolvidables veladas. Las ciudades de Marcelo Cohen son así cuerpos decrépitos con órganos en mal estado. Talecuona, Bardas de Krámer y Barrio de Tango son ciudades ${ }^{28}$ virtuales estampadas desde lo real que pulen la carcoma antes de dejar rienda suelta a la imaginación. Estas postales bocetadas no producen esperpento pero sí en cambio inquietan e incomodan. ${ }^{29}$

Es innegable que en los ejemplos citados anteriormente converjan símbolos nefastos: el encierro, la hibridación, el espejismo improductivo... En nuestra tesis doctoral, pudimos comprobar igualmente la segmentación urbana propia de las ciudades del Delta Panorámico, característica aplicable también a los conjuntos urbanos imaginados por Cohen antes de $2001^{30}$.

Las ciudades de las historias de nuestro autor pueden sin embargo vehicular otros valores. Ciertos estudios han mostrado que la ciudad "es uno de los símbolos de la madre" por su protección y sus límites ${ }^{31}$. En el interior de los conjuntos urbanos de los relatos y de las novelas de Cohen, se urden procesos complejos de resistencia frente a poderes hegemónicos (Krámer, Talecuona, Lavinca...), y se construye un contexto propicio a la emergencia de la palabra y de la escritura ${ }^{32}$. La ciudad da origen a nuevos seres: en Bardas de Krámer, al final de la novela, Ezequiel puede aspirar a formar una familia; en Ciudad Ajania, Viol Minago desencadena el entusiasmo de la población por la nueva actividad lingüístico-corporal constituida por la "Palabrística": componer, por medio de cuerpos humanos, palabras, expresiones y frases. Si la ciudad coheniana se presenta en general con los rasgos de una Babilonia posmoderna y alienante, constituye sin lugar a dudas la matriz de todas las creaciones de Cohen y en muchos casos genera en los protagonistas procesos activos, de creación, de búsqueda, de cuestionamiento. No es en vano precisar que la mayoría de las veces estas "eclosiones de sentido" se producen en zonas marginales de la ciudad (como, por ejemplo, Villa Canedo, o los suburbios de la capital de Impureza) y que lógicas de tensión centro-periferia dinamizan numerosas historias (El testamento de o'Jaral, Hombres amables, Donde yo no estaba, entre otras).

17 Después de haber estudiado las postulaciones principales que atañen a las ciudades en la obra de Marcelo Cohen, podemos profundizar las relaciones entre el río y la ciudad.

\section{El río y la ciudad en la literatura de Cohen: ¿relaciones huidizas?}

Siguiendo los criterios témporo-espaciales que presentamos anteriormente en cuanto a la obra de Cohen, podemos comenzar citando las relaciones existentes entre el río y la 
ciudad en sus dos primeros libros de cuentos de la primera mitad de los años 70. Dos relatos (uno en cada libro) contienen marcas explícitas de nexos entre estas dos figuras.

En el cuento más largo de Lo que queda -el sexto, titulado "El Pescador y su sombra"-, Cohen recupera la historia de un relato de Oscar Wilde de 1891, "El pescador y su alma", que proviene a su vez de una reescritura del cuento "La sirenita" de Andersen. La "pseudo-adaptación" de Cohen del cuento de Wilde mantiene los núcleos básicos (la historia de amor y de muerte entre un Pescador y una sirena), pero transforma el contexto de la acción, ya que la incluye en una ciudad: Buenos Aires ${ }^{33}$. La especificación relativa a la identidad precisa de la capital argentina se lleva a cabo en el nudo del cuento, cuando se evocan el tango, un conventillo y los piringundines de la calle 25 de Mayo. Pero, al comienzo, en lo que podríamos llamar el "prólogo" del cuento, se dan pistas generales que permiten al lector acercar los rasgos descriptivos iniciales a una Buenos Aires mítica:

Había una vez un hombre que tenía el oficio de pescar. Es decir que, como todos los hombres que tienen el oficio de pescar, este hombre era llamado Pescador. El Pescador vivía en una ciudad que tenía calles como tubos largos e iluminados de las que se enamoraban los poetas para cantarles como si fueran mujeres. Tenía además un río que todos los días lanzaba con su aliento un velo de palabras sobre la ciudad. (p. 41)

Después de un íncipit de cuento maravilloso que incluye la presentación del protagonista, los núcleos semánticos siguientes: una ciudad / los poetas / un río / un velo de palabras configuran una relación "intertextual" explícita inscrita en las dos figuras que nos conciernen: el río brinda palabras a la ciudad, la construye literariamente en cierto sentido... como los poetas. Comprobamos que desde la primera literatura de Cohen el río y la ciudad están íntimamente ligados a la palabra y a la escritura ${ }^{34}$.

21 Si bien este comienzo nos parece paradigmático, no se puede negar que este nexo (ríociudad) es bastante circunstancial, sobre todo porque el relato pasa a desarrollar una historia con un mar. En el segundo relato que queremos comentar, la relación entre las dos figuras es más fuerte, porque constituye un momento culminante de la historia: todo el relato prepara cuidadosamente la emergencia de la imagen que vehiculará el nexo entre las dos figuras. Se trata del cuento más breve (el cuarto del volumen, de cuatro páginas y media) de Los pájaros también se comen, titulado "El mar dulce"35.

Una vez más Buenos Aires, pero desde otra perspectiva, constituye el punto de convergencia de las miradas de dos amigos, el Rubio y Gerardo, los protagonistas del relato. Los dos adolescentes reman a bordo de dos botes en un canal que llaman el "Pacú" hasta el punto en que desemboca en el Río de la Plata. Después de asistir al "espectáculo" de la inmensidad del río, aparece la ciudad, en la descripción maravillada que recuerda vagamente el "prólogo" de "El Pescador y su sombra" de Lo que queda. Disfrutemos de la "puesta en escena" para la visión:

Gerardo miró adelante y sintió de golpe toda la sangre en la garganta. Las islas habían desaparecido por detrás. Se cortaron, Gerardo. Desaparecieron las islas. El Plata, Gerardo, todo el Plata. Ahí estaba, primero marrón, después gris y brillante como una plancha de metal gigantesca. ¿Cómo, y las islitas, y el Pacú? Nada, el Plata salpicado de lenguas blancas y allá al fondo quién sabría qué. Porque no había nada, solamente una inmensidad tremenda y miedo, Gerardo, miedo, olas que se hacen grandes, y más y más río y así hasta el mar. Río y el cielo azul desteñido, agua golpeando contra ella misma, un ruido violento. Y algo más: la ciudad, y [el Rubio] tuvo que apoyar el remo en los bordes de la canoa y reclinarse para mirar mejor, no podía hablar, ahora no era el cansancio sino otra cosa, la ciudad, un bloque deforme de edificios altísimos envueltos en una nube casi negra, ahí dentro vivía él, algo 
como los castillos encantados de las revistas de terror pero mucho más grande; al fin y al cabo era Buenos Aires. Y ahora la tenía enfrente, la miraba por encima del río más grande del mundo y la ciudad estaba a punto de caerse sobre esa densidad quieta y amenazante y sin embargo no se caía, solamente rugía y crecía y seguía envuelta en un espeso humo oscuro mientras las cabezas de los rascacielos se asomaban y volvían a esconderse como dedos rígidos entre cortinas. (p. 52, 53) que no lleva agua:

Era [...] incómodo que [Ramiro, el secretario de Ezequiel] hablara de agua ${ }^{37}$ en una ciudad inclinada sobre un cauce seco que, para colmo, desembocaba en un puerto ausente. De todos modos era mejor que el límite hubiera dejado las dársenas al otro lado; no sería estimulante la corrosión de las grúas asediadas por la maroma. (p. 11) al borde de un riacho medio exhausto, la ciudad creció bizarramente (p. 39)

El río que bordea esta ciudad está casi seco, y no hay fondeaderos con barcos que brillen como cráneos desnudos, barcos que esperen o salgan a pescar, y pasa una película entintada de petróleo rancio, $y$ en los travesaños de las torres flamean esqueletos de una estirpe de virreyes, $y$ es a lo lejos donde se hincha el resplandor de la vida que decide, las ciudades donde pasa algo. (p. 80, pasaje en cursivas en el original)

de los paseos por el río, en la época en que el río acarreaba agua (p. 121)

El paisaje urbano general es decadente desde todo punto de vista: tanto en las construcciones como en lo ecológico. No es asombroso en consecuencia que la ausencia de agua coincida con la presencia de polvo, con un proceso de desertificación que se asimila a la muerte ${ }^{38}$. 
29 Las modulaciones de la relación río-ciudad manifiestan otros matices en las novelas posteriores de Cohen. En el caso de El oído absoluto, el único nexo que vincula el río de Lorelei con el río seco de Krámer es el anonimato: "Un río sin nombre cruza Lorelei” (p. 19) es la frase inicial con la que comienza una larga descripción del estuario en donde están las islas que conforman Lorelei. Aquí el río actúa como "origen" del lugar: las islas fueron formadas por el estuario del río. Este también es un límite que hay que atravesar: los personajes que viven en la zona periférica deben cruzarlo para llegar al centro de Lorelei, en donde trabajan. La zona del puerto está vedada al público, precisamente porque allí se descubrirá luego un tráfico de desechos y basura. En cuanto a El testamento de O'Jaral, el río sí tiene nombre (el Talec), nombre que está en relación con el de la ciudad: Talecuona. Pocos contextos pueden ser citados para establecer una relación entre los dos motivos:

El río Talec atravesaba todos los anillos de la ciudad pasando por el centro. (p. 83)

Enfrente, en la otra margen [del río], dormitaban talleres y baldíos, dependencias

policiales, las canónicas viviendas en cadena del funcionariado. (p. 184)

En esta metrópoli (pos)industrial, el río forma parte de un decorado en el que se insiste en la fragmentación urbana y social. También se destacan la contaminación, el humo, los desechos y la basura. Todo esto configura un paisaje urbano decadente.

Con relación al último ciclo, al del Delta Panorámico, sólo nos concentraremos en su obra fundacional: Los acuáticos.

Además de las coordenadas de ciencia ficción (estadio futuro de la civilización, elementos tecnológicos y psicológicos imaginarios, como la Panconciencia), se puede decir que este "nuevo mundo" que construye Cohen se define por coordenadas geográficas territorializadas correspondientes, si no a lo argentino, sí a lo rioplatense: un río, un delta ${ }^{39} \mathrm{e}$ islas. La particularidad de los relatos de Los acuáticos es que cada uno (exceptuando el último) se desarrollará en una ciudad-isla del Delta Panorámico. Reflexionemos ahora sobre las relaciones entre el río y la ciudad en el Delta.

Primero cabe señalar que volvemos en este universo futurista al modelo del río anónimo de Bardas de Krámer y de Lorelei. El archipiélago infinito de islas fluviales se encuentra en un río cuyo nombre nunca se menciona. En segundo lugar, se puede comprobar, con matices y variaciones, un alejamiento, un contraste, una oposición, en suma, entre la ciudad y el río en estos relatos. Traigamos a colación unos cuantos ejemplos para determinar más precisamente la naturaleza de estas divergencias.

En el primer cuento largo, "El fin de la Palabrística", la acción tiene lugar en Ciudad Ajania, la principal y/o única urbe dominante de su isla. Porque, una vez en las afueras de la ciudad, traspasando la Ronda Perimetral, el paisaje que se obtiene es lo contrario a una ciudad desarrollada. Peor cuando la vista alcanza las costas:

Más lejos, cerca de las riberas, aldeas como de pan negro desmigajado. Ciertos pobladores rubios y ariscos que secan juncos. Pesca y cestería y unos cánticos de rana que parecen emitidos desde el centro del cráneo. Con la brea que flota en las rías esa gente hace enormes montículos que figuran en la guía turística de la isla pero en los diarios no aparecen nunca. Tortas de Aján, las llaman. Entre los sauces. Las he visto al ir en flaybús de vacaciones a Isla Guampol o a otra parte. Un álbum fotográfico de la angustia. ("El fin de la Palabrística", p. 313")

Se trata de un mundo precario, con actividades primarias (secar juncos, "pesca y cestería"). Se opone con esta descripción el mundo "avanzado", "civilizado" de la ciudad (con su febrilidad, sus rascacielos, su trajín) al contexto que se presenta como "atrasado" 
de las aldeas cercanas a las riberas del río. Lo alejado del centro neurálgico urbano es pintado con matices pasivos $\mathrm{y}$, por qué no, decadentes.

En "Un montón de adjetivos", el segundo relato, se ahonda la oposición "dentro de la islaciudad" vs. costas. Desde un salón de exposiciones del Hotel Isla Brunica, se puede contemplar por una ventana gigantesca la vida exterior de las riberas de la isla. Es lo que hace la artista plástica Leandra Chenán:

[...] como en la playa a oscuras donde dormían algunas sombrillas y donde unas varas más allá, en el barro espumoso que había dejado la bajante del río, una banda de isleños en botas de goma cazaba los cangrejos grises que eran casi la mayor riqueza exportable de Brunica. Salvo, pensó Leandra, que afuera hacía frío. ("Un montón de adjetivos", p. 342)

Se enuncia que los cangrejeros viven en chozas, casuchas y casas de lata en su aldea, y se opone el mundo del arte y la frivolidad de la exposición artística de la artista a la vida pobre y simple de los habitantes de la costa. El contraste socio-económico y cultural aquí se acentúa porque Leandra (exponente urbano por excelencia) realiza estancias experimentales en las chozas de la ribera para poder inspirarse de ese contexto en sus pinturas. En efecto, los veintiséis cuadros presentados en el hotel representan el mundo de los cangrejeros. El mundo pobre del río, al proveer la materia y el tema de inspiración artística, es utilizado con fines comerciales (venta de los cuadros) por la alta sociedad urbana de Isla Brunica.

En "Neutralidad", el cuarto cuento largo, se presenta una isla anónima dividida en dos países. Se alude a dos ríos: el del Delta (vamos a decir "exterior", que rodearía la isla) y un riacho que se encuentra en la frontera de los dos países vecinos. La frontera suma dos imágenes contradictorias: el río y el desierto.

En el desierto que tantas décadas costó crear ("Neutralidad", p. 395)

Entonces, junto con los cables del puente, entre los vahos de calor que suben de la arena, empiezan a hamacarse la pasarela, los pilares, las barrancas del río que el puente atraviesa y los médanos [...]. Millones de toneladas de arena traída de las playas de la isla debieron hacer falta para crear este espectáculo fronterizo. [...] También me han dicho [los taxistas] que antes este riacho era mucho más rumoroso. Ahora parece que se quejara; es un hilo atormentado que no brilla ni da idea de movimiento. (ibidem, p. 397)

La imagen "natural" de un riacho que se queja, casi exangüe, está conectada con el desierto "artificial" que ambos Estados han realizado. Como si la mano del hombre sofocara el ámbito natural para "desvitalizarlo".

En un segundo contexto, se ponen en relación las ciudades y el río. Se trata aquí del río que rodea la isla, no del riacho fronterizo. La narradora compara las playas y las actividades de los habitantes del país vecino con las suyas propias:

Playas como las nuestras, pero bordeadas de edificios craquelés. Todo de un color crema sin matices. Carteles de publicidad antediluvianos. Familias que usan las playas, que inexplicablemente nadan en el río, el río que nosotros pudimos olvidar porque tenemos piscinas convexas, comunitarias y privadas. Anticuados muelles donde no pocos se sientan a contemplar las olas marrones, acidulentas. Chicos que pescan. Individuos que no usan gafas de sol. [...] Una capital de vida lenta, medrosa, se dice que en partes destruida, donde ni siquiera se aprecian los dividendos del gasoducto que tendimos nosotros bajo el desierto. (ibídem, p. 405)

Se ve claramente que en las playas de la capital del Estado "del frente" los vecinos pescan, se bañan, contemplan la naturaleza en un contexto un poco decadente (el relato habla también de ruinas). Por el contrario, los habitantes del país de los mentalistas (el de la 
narradora) se han "olvidado" del río porque utilizan piscinas. El contraste se da entre modos de vida. En el que es juzgado más avanzado (el segundo), se prosigue con la constante del Delta Panorámico: la ciudad se aleja de la naturaleza.

En el último cuento largo del volumen, "Panconciencia. Un ensayo", el río mantiene una conexión indirecta con la ciudad. En una parte del relato se cuenta la infancia y la juventud de Wiraldo Sang, quien descubriría la Panconciencia. En un momento en que se hallaba en la playa de su isla (Isla Golasa), ve llegar a un pirata, Jacqués Clarant. Este venía a efectuar un rito fúnebre: quemar los cadáveres de dos compañeros suyos. El pirata hace que el joven Wiraldo participe en el rito, lo invita a subir a su embarcación y comienza la nueva vida de violencia y delincuencia de Wiraldo, como pirata del Delta Panorámico.

En Isla Golasa, las diferencias socio-económicas son enormes. Habitantes ricos viven en campos de exclusión, mientras que los pobres se concentran en chozas de villas miseria como la familia de Wiraldo. Se trata de un contexto urbano de disparidades y actos delictivos, de inseguridad en los dos ámbitos. De ahí toda la reflexión que se presenta con relación a la vida, no ya en la isla, sino en el río, como piratas:

Navegar hasta la muerte no era más promisorio ni tonificante que andar por tierra firme preguntándose cómo vivir; era una imposición que ellos [los piratas, compañeros de Jacqués Clarant] acataban dejándose albergar por el oleaje del río. Lo mismo que los otros humanos para algunos hombres, las islas eran para ellos el infierno. En el oleaje y las luces del oleaje y en los perfumes transitorios se reconocía al viento, y al viento le daban ellos su piel. ("Panconciencia. Un ensayo", p. 469)

Parafraseando el dicho "l'enfer, c'est les Autres" de la obra de teatro Huis clos de Jean-Paul Sartre, se pone de relieve que la vida en las islas era el infierno para los piratas. La vida fluvial de pirata es la libertad; la vida terrestre, el encierro y la imposibilidad de realizar su destino. Si la vida en las islas se acerca a la vida urbana, a la vida insegura en la ciudad, entonces se puede tender un puente entre el río y la ciudad. Los piratas truecan la inseguridad de la ciudad por la delincuencia asumida en el río. La diferencia fundamental está probablemente en la elección de su propio destino: el quedarse en tierra firme equivaldría a someterse a la violencia urbana como agente y víctima; el salir de la ciudad hacia la vida fluvial sería decidir una forma de vida errante, de libertad y de apertura.

\section{Ideas finales}

Hemos podido comprobar que la ciudad en Cohen reviste muchos valores, en general negativos. La urbe está asociada a lo patológico, a lo fragmentario, a lo decadente. Sin embargo, no debemos olvidar que se gestan en la ciudad mecanismos de resistencia y de creación. La palabra nace en la ciudad, se desarrolla y penetra en las estructuras más profundas para desestabilizarlas.

De Buenos Aires a las ciudades-islas del Delta Panorámico, la red de relaciones que pueden elaborarse entre el río y la ciudad no deja de ser una compleja telaraña facetada. En un principio, Buenos Aires y el Río de la Plata están conectados por la poesía y la literatura, con, por ejemplo, el intertexto de El Mar Dulce de Payró. En otros momentos posteriores de la creación literaria coheniana, el río puede ser anónimo o no y se encuentra en una relación ambivalente con la ciudad: casi inexistente en Bardas, omnipresente en Lorelei, motivo más bien circunstancial en Talecuona, el río se metamorfosea según el contexto novelesco. Por fin, en el Delta Panorámico, las relaciones 
huidizas entre río y ciudad tienden al contraste entre ambos más que a la complementariedad. Aunque paradójicamente el mundo del Delta Panorámico no puede existir sin su río infinito, el río se aleja en general de la ciudad, cuando esta enarbola las señas de lo avanzado, de lo moderno, de la civilización opuesta a lo que vendría a representar ciertas caras de la barbarie: la naturaleza, la pobreza, el atraso. Y aun cuando se considere que la isla pueda ser la hipóstasis de la violencia urbana, el río no escapa al mundo delictivo de la piratería. La diferencia esencial entre los dos modos de vida radica en que en la isla uno es agente y víctima de sumisión al destino impuesto, o bien se puede asumir la libertad errante del río.

\section{BIBLIOGRAFÍA}

Bergero Adriana J., "Desindustrialización, espacio global y gestión colectiva en Insomnio, de Marcelo Cohen", Hispamérica, vol. 31 / 93, 2002, p. 35-47, disponible en <http://www.jstor.org/ stable/10.2307/20540404>, página consultada el 23 de octubre de 2017.

Carré Marie-Noëlle y Oeyen, Annelies, "Vers une esthétisation des marges urbaines dans Impureza de Marcelo Cohen", Géographie et cultures, diciembre de 2011, p. 153-168, disponible en <http:// gc.revues.org/424>, página consultada el 23 de octubre de 2017.

Castellino, Marta Elena, “Utopía y distopía en El oído absoluto de Marcelo Cohen”, Revista de literaturas modernas, "Los espacios de la literatura", 2004, p. 67-84, disponible en <http:// bdigital.uncu.edu.ar/objetos_digitales/140/Castellino\%20RLM34.pdf et página consultada el 23 de octubre de 2017.

Chevalier Jean y Gheerbrant, Alain, Dictionnaire des symboles: mythes, rêves, coutumes, gestes, formes, figures, couleurs, nombres, París, R. Laffont y Éditions Jupiter, 2008.

Chiani, Miriam Neri, Cuando el narrador escucha. Sobre la presencia de la música en los textos críticos y narrativos de Marcelo Cohen [1973-2008], Universidad Nacional de La Plata, Facultad de Humanidades y Ciencias de la Educación, 2012, tesis doctoral disponible en <http://

www.memoria.fahce.unlp.edu.ar/library?a=d\&c=tesis\&d=Jte764>, página consultada el 23 de octubre de 2017.

-, "Prólogo" a El oído absoluto, Buenos Aires, Eudeba, 2013, “Serie de los Dos Siglos”, no 14, p. 9-24.

Cisterna, Gold María Inés, Exilio en el espacio literario argentino de la posdictadura, Woodbridge, Tamesis, 2013, disponible en <http://www.tamesisbooks.com/store/viewItem.asp? idProduct=14249>, página consultada el 23 de octubre de 2017.

Cittadini, Fernando (ed.), Mano a mano. Cuentos sobre tangos, Buenos Aires, Grupo Editorial Norma, 2004.

Cohen, Marcelo, Lo que queda, Buenos Aires, Ediciones L.H., 1972.

-, Los pájaros también se comen, Buenos Aires, Editorial Boedo, 1975.

-, Insomnio, Buenos Aires, Paradiso, 1994 [1985]. 
—,El testamento de O'Jaral, Buenos Aires / Madrid, Alianza Editorial / Anaya \& Mario Muchnik, 1995.

-, Inoubliables soirées / Inolvidables veladas, Francia, Maisons des Écrivains Étrangers et des Traducteurs de Saint-Nazaire, 1995.

_, El oído absoluto, Buenos Aires, Grupo Editorial Norma, 1997 [1989].

—, Los acuáticos. Historias del Delta Panorámico, Buenos Aires, Grupo Editorial Norma, 2001.

-, Impureza, Buenos Aires, Grupo Editorial Norma, 2007.

-, Relatos reunidos, Buenos Aires, Alfaguara, 2014.

Drucaroff, Elsa, “Atrapados y dormidos: Insomnio de Marcelo Cohen y algo más sobre las ficciones argentinas", disponible en <http://web.archive.org/web/20080128182720/http://

www.ciudaddearena.org/drucaroff_insomnio.html>, página consultada el 23 de octubre de 2017.

Estrade, Christian, “Postales urbanas del porvenir en la obra de Marcelo Cohen”, en María Angélica Semilla Durán, Jorge P. Santiago y François Laplantine (eds.), Utopies, enchantements et hybridité dans la ville ibérique et latino-américaine, París, Édition des archives contemporaines, 2012, p. 251-259.

Franco, Jean, “Estéticas urbanas: literatura y megalópolis”, en Ignacio Díaz Ruiz (ed.), Cultura en América: Deslindes de fin de siglo, México, UNAM, 2000, p. 15-34.

Gasparini, Sandra, "Palabras vigiladas. Las ciudades de fin de siglo en la narrativa de Marcelo Cohen", Actas del IX Congreso Nacional de Literatura Argentina, Universidad Nacional de Río Cuarto (Argentina), 2001.

Keizman, Betina, El complot fantástico, cinco aproximaciones, Universidad Autónoma de México, 2004, tesis doctoral inédita.

Logie, Ilse, "Avatares de un mito: manifestaciones del apocalipsis en la literatura contemporánea rioplatense: el caso de Insomnio de Marcelo Cohen", en Perla Petrich, Julio Premat y Maria Llombart (eds.), Les sujets contemporains et leurs mythes en Espagne et en Amérique latine, Alicante, Biblioteca Virtual Miguel de Cervantes, 2008, disponible en <http://www.biblioteca.org.ar/ libros/141022.pdf>, página consultada el 23 de octubre de 2017.

-, “En busca de lo nuevo: El testamento de O'Jaral (1995) de Marcelo Cohen”, Revista de Crítica Literaria Latinoamericana, vol. 37 / 74, 2011, p. 171-191, disponible en <https://biblio.ugent.be/ publication/1148207/file/6747500.pdf>, página consultada el 23 de octubre de 2017.

McHale, Brian, Postmodernist fiction, Londres, Routledge, 2001.

Oeyen, Annelies, “Ciudades posapocalípticas en la literatura prospectiva de la Argentina posdictatorial”, Ángulo Recto. Revista de estudios sobre la ciudad como espacio plural, vol. 3 / 2 , noviembre de 2011, p. 225-245, disponible en <http://www.ucm.es/info/angulo/volumen/ Volumen03-2/varia07.htm>, página consultada el 23 de octubre de 2017.

-, Escrituras del derrumbe. Ciudades posapocalípticas: Marcelo Cohen y la narrativa argentina posdictatorial, Universiteit Gent, 2011, tesis doctoral inédita.

-, "La caminata urbana construye espacios literarios: un análisis de 'Cuando aparecen Aquéllos' de Marcelo Cohen”, RILCE: Revista de filología hispánica, vol. 29 / 1, 2013, p. 99-114, disponible en <http://dspace.unav.es/dspace/handle/10171/34225>, página consultada el 23 de octubre de 2017. 
-, "Hacia una (est)ética del posapocalipsis en la narrativa argentina posdictatorial", Revista Iberoamericana, LXXX, 2014, p. 631-652, disponible en <https://biblio.ugent.be/ publication/1123446/file/6746906.pdf>, página consultada el 23 de octubre de 2017.

Payró, Roberto J., El Mar Dulce. Crónica romancesca del descubrimiento del Río de La Plata, Buenos Aires: Gleizer, 1927.

Reati, Fernando O., Postales del porvenir: la literatura de anticipación en la Argentina neoliberal (1985-1999), Buenos Aires, Editorial Biblos, 2006.

Sarlo, Beatriz, Escritos sobre literatura argentina, Buenos Aires, Siglo Veintiuno Editores Argentina, 2007.

Steimberg, Alejo, "El futuro obturado: el cronotopo aislado en la ciencia ficción argentina pos-2001”, Hélice: Reflexiones críticas sobre ficción especulativa, vol. 1 / 14, enero 2012, p. 4-19, disponible en <http://www.revistahelice.com/revista/Helice_14.pdf>, página consultada el 23 de octubre de 2017.

-, "El postapocalipsis rioplatense de Marcelo Cohen. Una lectura de Donde yo no estaba", en Geneviève Fabry, Ilse Logie y Pablo Decock (eds.), Los imaginarios apocalípticos en la literatura hispanoamericana contemporánea, Peter Lang, Berna, 2010, p. 245-255.

Torre, Ricardo, “El diálogo entre los textos de Lo que queda de Marcelo Cohen”, en Milagros Ezquerro y Julien Roger (eds.), Le texte et ses liens II, vol. 1. Université Paris-Sorbonne, Les Ateliers du Séminaire Amérique Latine, 2007, disponible en <http://crimic-sorbonne.fr/actes/tl2/ torre.pdf>, página consultada el 23 de octubre de 2017.

-, L'œuvre de Marcelo Cohen : entre sociologie fantastique et géographie imaginaire, Université Paris-Est Créteil Val de Marne, 2016, tesis doctoral inédita.

Westphal, Bertrand, La Géocritique : réel, fiction, espace, Paris, Les Éditions de Minuit, 2007.

\section{NOTAS}

1. La obra narrativa de ficción de Marcelo Cohen constituye la bibliografía-fuente principal de este estudio. Es decir, unos veinte volúmenes (libros de cuentos, novelas cortas y novelas), desde su primer libro de relatos (Lo que queda, Buenos Aires, Ediciones L. H., 1972) hasta su novela Algo más (Buenos Aires, Sigilo, 2016 [1ª edición: Páprika, 2015]).

2. Para evitar toda ambigüedad, queremos aclarar que el exilio de Cohen en España (de 1975 a 1996) fue voluntario.

3. Fernando Cittadini (ed.), Mano a mano. Cuentos sobre tangos, Buenos Aires, Grupo Editorial Norma, 2004. El relato de Cohen es el décimo y último del conjunto (p. 189-270).

4. Marcelo Cohen, Impureza, Buenos Aires, Grupo Editorial Norma, 2007.

5. Hemos desarrollado nuestras hipótesis sobre esta novela en nuestra tesis doctoral: Ricardo Torre, L'œuvre de Marcelo Cohen: entre sociologie fantastique et géographie imaginaire, Université Paris-Est Créteil Val de Marne, 2016, p. 179-183, tesis inédita.

6. Observaciones: 1 . No se presenta exhaustivamente toda la obra de Cohen. Se ha hecho un recorte de los libros pertinentes para la presente reflexión. 2. Las líneas punteadas que limitan la novela Impureza intentan mostrar el valor transicional de esta obra (entre las dos últimas décadas del siglo XX y la producción del Delta Panorámico del siglo XXI). 3. La indicación (N) que acompaña algunos libros significa que se trata de una novela. 4. Impureza, Balada y Gongue tienen una extensión comparable (entre alrededor de 80 y 130 páginas), pudiendo considerárselas como nouvelles o novelas cortas. Lo hemos indicado como novela. 
7. Christian Estrade, "Postales urbanas del porvenir en la obra de Marcelo Cohen", en María Angélica Semilla Durán, Jorge P. Santiago y François Laplantine (eds.). Utopies, enchantements et hybridité dans la ville ibérique et latino-américaine, París, Édition des archives contemporaines, 2012, p. 251-259.

8. Bertrand Westphal, La Géocritique : réel, fiction, espace, París, Les Éditions de Minuit, 2007, p. 172 y ss. En francés: "brouillage hétérotopique"; la traducción es nuestra.

9. Brian McHale, Postmodernist fiction, Londres, Routledge, 2001.

10. Ricardo Torre, op. cit.

11. Sandra Gasparini, "Palabras vigiladas. Las ciudades de fin de siglo en la narrativa de Marcelo Cohen", Actas del IX Congreso Nacional de Literatura Argentina, Universidad Nacional de Río Cuarto, 2001, p. 71-76.

12. Elsa Drucaroff, “Atrapados y dormidos: Insomnio de Marcelo Cohen y algo más sobre las ficciones argentinas", disponible en <http://web.archive.org/web/20080128182720/http:// www.ciudaddearena.org/drucaroff_insomnio.html>, página consultada el 23 de octubre de 2017, p. 6.

13. Adriana J. Bergero, "Desindustrialización, espacio global y gestión colectiva en Insomnio, de Marcelo Cohen”, Hispamérica, vol. 31 / 93, 2002, p. 35-47, disponible en <http://www.jstor.org/ stable/10.2307/20540404>, página consultada el 23 de octubre de 2017.

14. Ibidem.

15. Elsa Drucaroff, op. cit. e Ilse Logie, “Avatares de un mito: manifestaciones del apocalipsis en la literatura contemporánea rioplatense: el caso de Insomnio de Marcelo Cohen”, en Perla Petrich, Julio Premat y Maria Llombart (eds.). Les sujets contemporains et leurs mythes en Espagne et en Amérique latine, Alicante, Biblioteca Virtual Miguel de Cervantes, 2008.

16. Elsa Drucaroff, op. cit. e Ilse Logie, op. cit.

17. Ilse Logie, op. cit. y Annelies Oeyen, Escrituras del derrumbe. Ciudades posapocalípticas: Marcelo Cohen y la narrativa argentina posdictatorial, Universiteit Gent, 2011 y "Hacia una (est)ética del posapocalipsis en la narrativa argentina posdictatorial”, Revista Iberoamericana, LXXX, 2014, p. 631-652, disponible en <https://biblio.ugent.be/publication/1123446/file/6746906.pdf>, página consultada el 23 de octubre de 2017.

18. Logie y Oeyen insisten en la idea del "cataclismo" que se produjo en Bardas de Krámer para poder fundamentar la calificación "posapocalíptica" de la ciudad y de la novela de Cohen. Nos preguntamos: ¿hubo realmente un cataclismo en Bardas de Krámer? La verdadera catástrofe para la ciudad, primero, y para el resto de Latinoamérica, después por sus consecuencias, fue el agotamiento de los pozos de petróleo. Pensamos que, tal vez, en la base de todo el planteo "posapocalíptico" endilgado a la urbe y a la ficción cohenianas exista una confusión. En el único lugar (la palabra es un hápax en la novela) donde se habla de "cataclismo" (hablando de los "privilegios" obtenidos por unos pocos amigos del fundador de la ciudad de parte del gobierno argentino, y a raíz del carácter de autonomía relativa de la urbe, se dice: "Les permitieron comercializar por cuenta propia el petróleo crudo a cambio de un impuesto anual que pagaría con mucho el cataclismo que se avecinaba.", p. 30 y 40 de la novela; citamos por la edición de 1994), se hace claramente alusión a los efectos del agotamiento del petróleo: la barbarie desencadenada por "las carradas de desocupados" (p. 40) en varias ciudades latinoamericanas.

19. Cf. Beatriz Sarlo, Escritos sobre literatura argentina, Buenos Aires, Siglo Veintiuno Editores Argentina, 2007; Jean Franco, "Estéticas urbanas: literatura y megalópolis", en Ignacio Díaz Ruiz (ed.), Cultura en América: Deslindes de fin de siglo, México, UNAM, 2000, p. 15-34 y p. 27-30; Marta Elena Castellino, "Utopía y distopía en El oído absoluto de Marcelo Cohen", Revista de literaturas modernas, "Los espacios de la literatura", 2004, p.67-84, disponible en <http:// bdigital.uncu.edu.ar/objetos_digitales/140/Castellino\%20RLM34.pdf et>, página consultada el 23 de octubre de 2017; Fernando O. Reati, Postales del porvenir: la literatura de anticipación en la 
Argentina neoliberal (1985-1999), Buenos Aires, Editorial Biblos, 2006 y Miriam Chiani, "Prólogo" a El oído absoluto, Buenos Aires, Eudeba, 2013, (“Serie de los Dos Siglos”, no 14), p. 9-24.

20. Ilse Logie, "En busca de lo nuevo: El testamento de O'Jaral (1995) de Marcelo Cohen”, Revista de Crítica Literaria Latinoamericana, vol. 37 / 74, 2011, p.171-191, disponible en <https:// biblio.ugent.be/publication/1148207/file/6747500.pdf>, p. 5 de la versión electrónica, página consultada el 23 de octubre de 2017.

21. Annelies Oeyen, "Ciudades posapocalípticas en la literatura prospectiva de la Argentina posdictatorial", Ángulo Recto. Revista de estudios sobre la ciudad como espacio plural, vol. 3 / 2, noviembre 2011, p. 225-245, disponible en <http://www.ucm.es/info/angulo/volumen/ Volumen03-2/varia07.htm>, página consultada el 23 de octubre de 2017. Christian Estrade, op. cit. 22. Marie-Noëlle Carré y Annelies Oeyen, "Vers une esthétisation des marges urbaines dans Impureza de Marcelo Cohen", Géographie et cultures, diciembre de 2011, p. 153-168, disponible en <http://gc.revues.org/424>, página consultada el 23 de octubre de 2017.

23. Annelies Oeyen, "La caminata urbana construye espacios literarios: un análisis de "Cuando aparecen Aquéllos' de Marcelo Cohen", RILCE: Revista de filología hispánica, vol. 29 / 1, 2013, p. 99-114, disponible en <http://dspace.unav.es/dspace/handle/10171/34225>, página consultada el 23 de octubre de 2017.

24. Si Buenos Aires aparece explícitamente en los cuentos de Cohen de los años 70, se manifiesta de manera oblicua en los años 80 y 90, ora en las historias de Villa Canedo, ora como el arquetipo en negativo de todas las ciudades de su producción. Los críticos identifican muy a menudo las ciudades ficticias de Cohen con Buenos Aires. Buenos Aires permanece a las puertas del Delta Panorámico con su reelaboración futurista en "Tristezas de una tarde de sábado" (1999, recogido en Relatos reunidos, Buenos Aires, Alfaguara, 2014).

25. Curiosa es la caracterización de la ciudad de Insomnio realizada por Cisterna Gold: "La novela transcurre en una isla en la Patagonia argentina, separada del territorio nacional por un río que se secó hace años", María Inés Cisterna Gold, Exilio en el espacio literario argentino de la posdictadura, Woodbridge (Reino Unidos), Tamesis, 2013, p. 84. Es evidente que hay que comprender "isla" aquí en un sentido metafórico.

26. Si entramos en juegos de identificación referencial, con respecto a Talecuona, mientras que Oeyen la considera el prototipo de la ciudad fragmentada y posapocalíptica y la compara con Buenos Aires (Annelies Oeyen, "Ciudades posapocalípticas...", op.cit., p. 232-237; para la comparación, cf. p. 234), Logie, por su parte, indica que Talecuona presenta rasgos comparables a los de una ciudad argentina del interior del país (Ilse Logie, "En busca de...", op. cit., p. 5). En todo caso, compartimos el punto de vista de Keizman, quien realiza una observación muy pertinente a este respecto: “Talecuona y algunas de las otras geografías a las que se hace referencia en el libro [El testamento de O'Jaral] parecen remitir a paisajes y espacios argentinos. Sin embargo, sería fútil lanzarse a una caza de citas para certificar aparentes correspondencias porque la geografía de Talecuona coincide parcialmente con el espacio porteño tanto como se aleja de él. Más que buscar similitudes o diferencias con el referente sospechado, interesa detenerse en qué tipo de ciudad se construye [...]". (Betina Keizman, El complot fantástico, cinco aproximaciones, Universidad Autónoma de México, 2004, p. 120, nota 146, tesis doctoral inédita.)

27. Oeyen pone de relieve la analogía entre Talecuona y un organismo enfermo, analogía planteada por las descripciones internas de El testamento de O'Jaral (Annelies Oeyen, ibidem, p. 233).

28. Sería menester precisar: "Barrio de Tango" (que se llamaba en realidad "Luna y Misterio") no es una ciudad sino uno de los barrios de "ciudad del tango".

29. Christian Estrade, op. cit., p. 253.

30. Ricardo Torre, op. cit. 
31. Jean Chevalier y Alain Gheerbrant, Dictionnaire des symboles: mythes, rêves, coutumes, gestes, formes, figures, couleurs, nombres, París, R. Laffont y Éditions Jupiter, 2008, p. 1015, destacado de los autores.

32. Christian Estrade, op. cit., pp. 256-259.

33. Miriam Neri Chiani, Cuando el narrador escucha. Sobre la presencia de la música en los textos críticos y narrativos de Marcelo Cohen [1973-2008], Universidad Nacional de La Plata. Facultad de Humanidades y Ciencias de la Educación, 2012, tesis doctoral disponible en <http:// www.memoria.fahce.unlp.edu.ar/library?a=d\&c=tesis\&d=Jte764>, página consultada el 23 de octubre de 2017, p. 182 y ss. Retomo el resumen del relato que incluimos en otro trabajo: "Un Pescador se enamora de una Sirena que encuentra en las redes que echa en el mar que tiene en el jardín del fondo de su casa. Para irse a vivir con ella, debe cortarse la sombra. Una mujer (una medio bruja, que comprendemos prostituta de un conventillo de la calle 25 de mayo, en Buenos Aires, se supone) le brinda la manera de hacerlo con un cortaplumas de oro". Ricardo Torre, "El diálogo entre los textos de Lo que queda de Marcelo Cohen", en Milagros Ezquerro y Julien Roger (eds.). Le texte et ses liens II, vol. 1. Université Paris-Sorbonne, Les Ateliers du Séminaire Amérique Latine, 2007, disponible en <http://crimic-sorbonne.fr/actes/tl2/torre.pdf>, página consultada el 23 de octubre de 2017, p. 4.

34. A pesar del "giro realista" evocado por Chiani, es importante subrayar que Cohen conserva en su relato el tono de cuento popular maravilloso, con, por ejemplo, personajes anónimos y elementos inverosímiles (un mar en un jardín). Reubicando en Buenos Aires una historia con una tradición literaria reconocida (Andersen, Wilde), el relato coheniano encierra una tensión entre localización precisa y cuento maravilloso.

35. La intertextualidad con la novela de Roberto J. Payró, El Mar Dulce. Crónica novelesca [ romancesca en la primera edición] del descubrimiento del Río de la Plata, Buenos Aires, Gleizer, 1927, es explícita. Es en su capítulo XVII donde los navegantes españoles, al mando de Juan Díaz de Solís, descubren en febrero de 1516 "el mar dulce", el río más ancho del mundo: el Río de la Plata. 36. Como lo hemos indicado, y a manera de balance final sobre la ciudad, la capital argentina representa en Los pájaros también se comen el punto de convergencia de las miradas de los protagonistas (en "El mar dulce"). En suma, Buenos Aires es el centro de un tablero narrativo que no es solamente "realista", puesto que Cohen elige describir el espacio con ecos de discursos pasados (la novela El Mar Dulce, de Payró, por ejemplo); esta "realidad" está por tanto tejida de discursos.

37. Ramiro acababa de pronunciar el refrán "cuando el río suena, aguas trae” (p. 11).

38. Elsa Drucaroff, op. cit.; Ilse Logie, "Avatares...", op.cit.; Annelies Oeyen, "Ciudades posapocalípticas...", op. cit.

39. Alejo Steimberg, "El postapocalipsis rioplatense de Marcelo Cohen. Una lectura de "Donde yo no estaba", en Los imaginarios apocalípticos en la literatura hispanoamericana contemporánea, Berne, 2010, p. 245-255 y "El futuro obturado: el cronotopo aislado en la ciencia ficción argentina pos-2001", Hélice: Reflexiones críticas sobre ficción especulativa, vol. 1 / 14, enero de 2012, p. 4-19, disponible en <http://www.revistahelice.com/revista/Helice_14.pdf>, página consultada el 23 de octubre de 2017.

40. La paginación de los relatos de Los acuáticos corresponde a su última edición en el volumen Relatos reunidos, citado anteriormente. 


\section{RESÚMENES}

El río y la ciudad constituyen dos ejes temáticos esenciales en la obra del escritor argentino Marcelo Cohen (Buenos Aires, 1951). Ya desde sus primeros cuentos (años 70), la vida urbana de Buenos Aires se halla presente en el mundo laboral desencarnado, en los recorridos citadinos de los personajes o en las oposiciones socioeconómicas. Con relación, esta vez, al río, este es vehículo de la experiencia y medio para alcanzar la revelación de la ciudad. Si los especialistas han privilegiado el estudio de las ciudades de la producción del autor argentino (por ejemplo: Bardas de Krámer en Insomnio, 1985; Lorelei en El oído absoluto, 1989), la relación entre el río y la ciudad no ha despertado la atención que merece. Proponemos hacer una síntesis crítica de los trabajos académicos aludidos (Drucaroff, Gasparini, Chiani, Logie, Oeyen) y extender la investigación a toda la obra de Marcelo Cohen. Por lo demás, en la producción literaria de Cohen de los últimos años, la relación ciudad-río se ha reforzado claramente a partir de la creación del universo del Delta Panorámico desde Los acuáticos (2001): un nuevo mundo ubicado en el futuro, conformado por un archipiélago infinito de islas de agua dulce, de islas fluviales.

Le fleuve et la ville constituent deux axes thématiques essentiels dans l'œuvre de l'écrivain argentin Marcelo Cohen (Buenos Aires, 1951). Dès ses premiers récits (années 70), la vie urbaine de Buenos Aires est bien présente dans le monde du travail désincarné, dans les parcours en ville des personnages ou dans les oppositions socio-économiques. Le fleuve est, quant à lui, véhicule de l'expérience et moyen d'atteindre la révélation de la ville. Si les villes ont été privilégiées par les spécialistes dans leurs recherches sur la production de l'auteur argentin (par exemple: Bardas de Krámer dans Insomnio, 1985 ; Lorelei dans El oído absoluto, 1989), le lien entre le fleuve et la ville n'a pas vraiment attiré l'attention qu'il mérite. Nous proposons de faire une synthèse critique des travaux académiques sur la ville (Drucaroff, Gasparini, Chiani, Logie, Oeyen) et d'étendre la recherche à toute l'œuvre de Marcelo Cohen. Par ailleurs, dans la production littéraire de Cohen des dernières années, le lien ville-fleuve s'est nettement renforcé à partir de la création de l'univers du Delta Panoramique depuis Los acuáticos (2001) : un nouveau monde placé dans l'avenir, constitué d'un archipel infini d'îles d'eau douce, d'îles fluviales.

The river and the city constitute two essential thematic axes in Argentine writer Marcelo Cohen's work (Buenos Aires, 1951). From his first stories ('70s), the urban life of Buenos Aires is present in the disincarnated working world, in the personages' city walk or in the socioeconomic oppositions. With regard, this time, to the river, this is a vehicle of experience and a means to achieve the revelation of the city. If the specialists have privileged the study of the cities in Argentine author's production (for example, Bardas de Krámer in Insomnio, 1985; Lorelei in El oído absoluto, 1989), the relation between the river and the city has not attracted attention it deserves. We propose to do a critical synthesis of these academic works (Drucaroff, Gasparini, Chiani, Logie, Oeyen) and to extend the research to the whole Marcelo Cohen's work. By the rest, in Cohen's literary production of last years, the city-river relationship has been clearly reinforced from the creation of the Panoramic Delta universe from Los acuáticos (2001): a new world located in the future, shaped by an infinite archipelago of islands of sweet water, of fluvial islands. 
ÍNDICE

Keywords: Marcelo Cohen, river, city, Argentine literature 20th century, Argentine literature 21st century

Palabras claves: Marcelo Cohen, río, ciudad, literatura argentina del siglo XX, literatura argentina del siglo XXI

Mots-clés: Marcelo Cohen, fleuve, ville, littérature argentine du XXe siècle, littérature argentine du XXIe siècle

\section{AUTOR}

\section{RICARDO TORRE}

Université Paris-Est Créteil, ATER

rstorre1@yahoo.fr 